\title{
Helminth infections in light of an ongoing intervention in endemic areas of Guragae zone, Southern Ethiopia: an implication for neglected tropical diseases elimination in Ethiopia by 2020
}

Teha Shumbej $^{1^{*}}$ and Tadele Girum ${ }^{2}$

\begin{abstract}
Introduction: Helminth infections are among the major public health problems in developing countries. Considerable efforts have been made towards the control of morbidity caused by infection with helminths in Ethiopia. The national control program is designed to achieve the elimination of helminth infections as a major public health problem by 2020.

Objective: The objective of this study was to determine the current status and infection intensity of helminths in the endemic area of Guragae zone, Southern Ethiopia.

Methods: An institutional based cross-sectional study was carried out between April and June 2017 in Gurage zone. School-aged children (SAC) were selected using a multistage sampling method and invited to participate in the study. Parasitological test examination was done using the Kato-Katz technique in Wolkite University parasitology laboratory. SPSS version 21 was used for data management and analysis.
\end{abstract}

Results: A total of 597 (98\% compliance rate) participants were able to provide complete data. The study revealed that $21.6 \%$ (129/597) SAC were infected with one or more species of helminth. S. mansoni was the most prevalent helminth (12.9\%) followed by hookworms (4.3\%). The overall infection intensity expressed as geometric mean for A. lumbricoides, T. trichiura, hookworms, and S. mansoni were 301, 31,103, and 158 eggs per gram of stool, respectively. The multivariable logistic regression model estimated that being in the age group of 59 years ( $A O R=1.43,95 \% \mathrm{Cl} 0.4-0.9$ ), washing raw food and vegetables using river water ( $\mathrm{AOR}=2.4,95 \% \mathrm{Cl} 0.16-0.75$ ), and a regular bathing habit in river ( $\mathrm{AOR}=2.14,95 \% \mathrm{Cl} 0.3-0.9)$ were independent predictors of helminth infections.

Conclusion: Despite the fact that Ethiopia planned to eliminate helminth infection-related morbidity by 2020, this study showed that helminth infection is prevalent in the study area. Efforts should be made to improve hygienic practices of the schoolchildren in addition to school-based deworming. Moreover, the deworming program should also focus on reaching those SAC who do not attend school through communal social places to achieve the targeted goal in the study area in particular and nationwide in general.

Keywords: Helminths, School-aged children, Guragea zone, Ethiopia

\footnotetext{
* Correspondence: shumbejt@gmail.com

'Department of Medical Laboratory Sciences, College of Medicine and

Health Sciences, Wolkite University, Wolkite, Ethiopia

Full list of author information is available at the end of the article
}

(c) The Author(s). 2019 Open Access This article is distributed under the terms of the Creative Commons Attribution 4.0 International License (http://creativecommons.org/licenses/by/4.0/), which permits unrestricted use, distribution, and reproduction in any medium, provided you give appropriate credit to the original author(s) and the source, provide a link to the Creative Commons license, and indicate if changes were made. The Creative Commons Public Domain Dedication waiver (http://creativecommons.org/publicdomain/zero/1.0/) applies to the data made available in this article, unless otherwise stated. 


\section{Background}

Helminths are parasitic worms, widely distributed throughout the world causing large threats to the public health, economy, and physical and cognitive development particularly among SAC in developing countries $[1,2]$ and result in significant morbidity and mortality in endemic countries. The World Health Organization (WHO) estimates approximately 1.5 billion people are infected with soil-transmitted helminths (STHs) and that 207 million people currently have schistosomiasis, 90\% of whom are living in Sub-Saharan Africa (SSA) [3, 4].

It is estimated that there are about 135, 000 deaths per year directly due to helminth infection around the globe [5]. Helminths are the main public health problem in many parts of the world. The principal public health significance of helminth infections lies in their chronic effects $[6,7]$. The negative effect of helminth infection is common with heavy infection intensity in SAC [8]. Schistosomiasis and STHs are among the most widely distributed neglected tropical diseases affecting people living in tropical and developing countries [9]. Most infections with helminth occur in poor communities [10], where the biophysical, cultural, and environmental factors favor helminth transmission [11].

Low standard of living, poor personal hygiene, unsanitary waste management, and unsafe and inadequate water supply are some the factors that favor rapid transmission of helminths in developing countries [12]. Prevalence of STHs and Schistosoma mansoni (S.mansoni) across Africa estimated that Ethiopia to have the 13th highest prevalence of each diseases group among over 40 countries [13]. In Ethiopia, an estimated 37.3 million people are living with schistosomiasis, and 79 million live in schistosomiasis and STHs in endemic areas. Helminth infections constitute the greatest cause of illness and diseases in Ethiopia [14]. Several studies showed helminth infections due to S.mansoni and STHs are widely distributed in Ethiopia affecting mainly SAC [15-18]. Intestinal parasite infections including helminth infections are a significant health problem in Guragae zone. The overall prevalence of intestinal parasite infection was ranging between 38.5 and $40 \%$ before deworming is launched in the study area [19].

Currently, the primary control strategy for helminths mainly depends on mass drug administration (MDA) provided for the population at risk including SAC. WHO recommends MDA annually when the infection prevalence is in between 20 and $50 \%$ or bi-annually when the prevalence exceed 50\% [9]. The national MDA program, launched since 2015 in Ethiopia, aims to eliminate STHs and schistosomiasis-related morbidity by 2020 [14]. Moreover, the MDA program goal in Ethiopia includes treating at least $75 \%$ of SAC in endemic districts [20]. Even though MDA does not prevent re-infection, repeated MDA has been known to have a considerable impact on maintaining the infection intensity of helminths to a minimal level and reducing the associated morbidities among infected individuals [21]. Therefore, this study aimed to determine the current status and infection intensity of helminth infections among SAC in the endemic area of Guragae zone, Southern Ethiopia, after 3 years of repeated deworming.

\section{Methods}

\section{Study design and settings}

An institution-based cross-sectional study was carried out between April to June 2017 in Gurage zone, Southern Nations, Nationalities, and People's Regional State of Ethiopia. The zone is located at altitude ranging from 1600 to $2800 \mathrm{~m}$ above sea level. The mean maximum and minimum annual temperature of the zone is $25^{\circ} \mathrm{C}$ and $7{ }^{\circ} \mathrm{C}$, respectively.

\section{Study population and sampling technique}

A single population proportion formula was used to calculate the sample size required for the study, with an assumption of the estimated prevalence of $23.3 \%$ [22], 95\% confidence level, a desired precision of 5\%, assuming additional $10 \%$ non-response rate, and a design effect of 2. Accordingly, the overall sample size calculated was 604 SAC. The proportionate number of study participant from each selected public elementary school was determined and each study subject was recruited using a systematic sampling technique as illustrated in Fig. 1.

\section{Inclusion and exclusion criteria}

All children aged between 5 and 14 years children who were available in their school during data collection time were included. If selected children were not in class at the time of the survey visit, the next student on the sampling frame was considered and those who did not provide stool samples were excluded.

\section{Data collection procedure and data quality control}

Data were collected using a semi-structured questionnaire. The questionnaire was initially prepared in English and then translated into Amharic and translated back into English to check its consistency by the principal investigator. A single fresh stool sample was collected from each study participants using clean, dry, and wide-mouthed labeled stool cups. Parasitological examination of stool samples was done in Wolkite University parasitology laboratory using the Kato-Katz egg counting technique. Briefly, the technique depends on microscopic counting of helminths and schistosome eggs in prepared slides with special staining of known weight of stool for helminth identification and enumeration as described elsewhere [23]. Infection intensities of the 


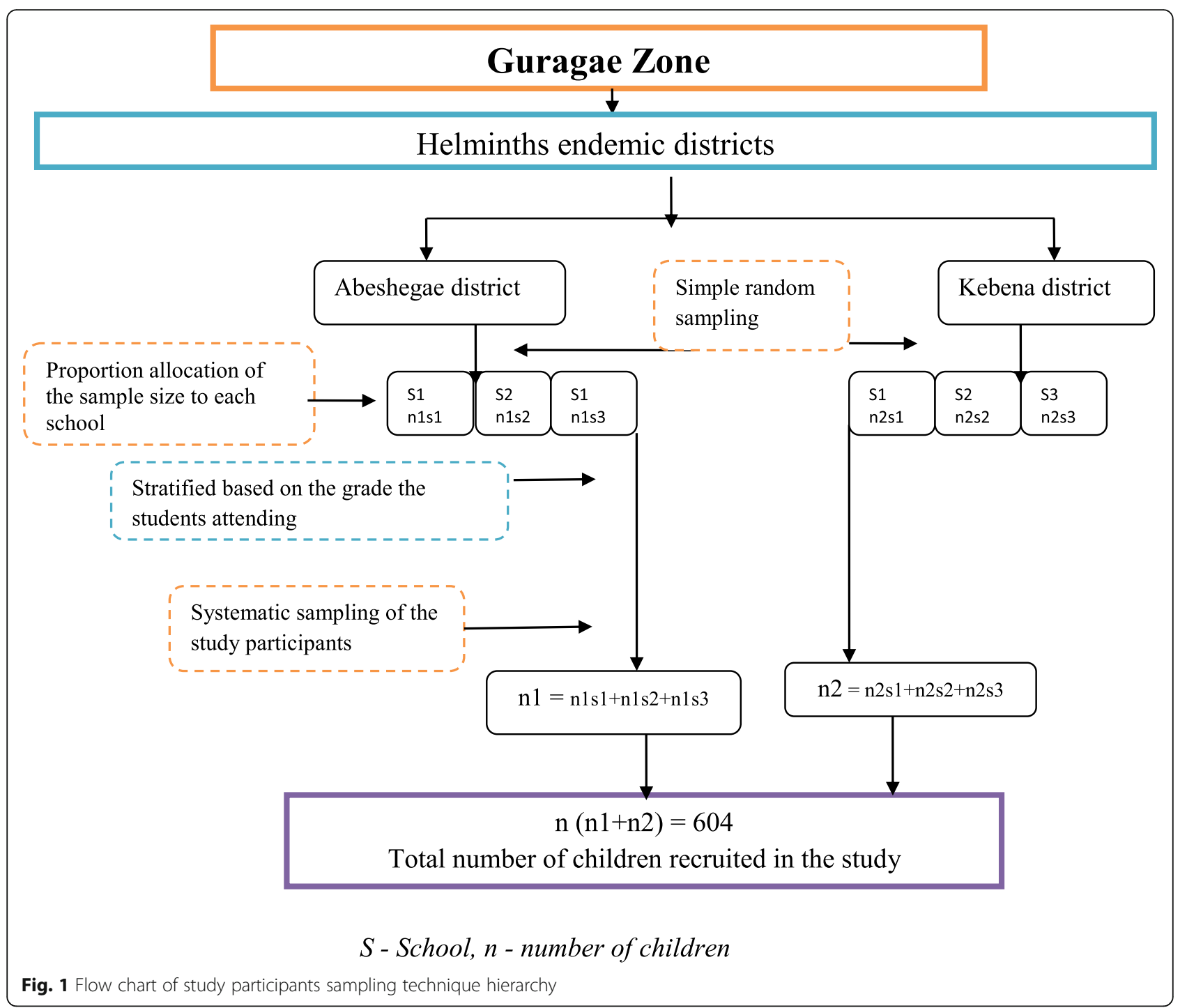

helminths were recorded and graded as light, moderate, or heavy based on the number of eggs per gram (EPG) of stool according to WHO threshold [24].

\section{Quality assurance}

Data collectors were trained in data collection and laboratory procedure. Data collected using the questionnaire was checked for completeness at the end of each day. Duplicate Kato-Katz slides were prepared from each sample, and the slides were read by two different microscopists. Standard operating procedures were followed in every step of the laboratory analysis.

\section{Data processing and analysis}

Data were entered, cleaned, and analyzed using SPSS for windows version 21 (Chicago, USA). The prevalence of helminths was calculated as the ratio of the number of children found positive for any helminth species to the total number of children who provided complete data. A co-linearity check was performed. Bivariate analysis was used to identify the associations of helminth infections with independent variables. All variables with $P$ value less than 0.25 in the bivariate analysis were analyzed using multivariable logistic regression model. $P$ values less than 0.05 were considered statistically significant.

\section{Study variables}

The study variable includes sociodemographic characteristics (age, sex, residence, family unit size), family status (occupation of mother, educational status of the mother, occupation of father, educational status of the father), hygienic factors (shoe wearing, hand washing habit, habit of nail biting, habit of playing in the soil), source of water, and helminth infections. 


\section{Results}

Demographic characteristics of the study participants A total of 597 (98\%) SAC was involved in this study. Age of the children ranged from 5 to 14 years with a median age of 10 years. The age group distribution showed that more than half $(53.2 \%)$ were in the age group of 59 years. More than half (58.7\%) of the children were males, and $59.1 \%$ of the households had a family size unit of between five and ten. About half (49.1\%) of the children's fathers and 46.3\% mothers (guardians) had primary education while $63.1 \%$ of the children's mothers and $65.1 \%$ children's fathers were housewife and farmers in occupation, respectively(Table 1).

\section{Prevalence and infection intensity of helminth infections}

Overall, at least one species of helminths was detected in 129 (21.6\%) of the SAC, of which 12.9\% (77/597) had S.mansoni (Table 3). Prevalence of helminth infection was associated with the age group of $5-9$ years $(P=0.03)$. There was no significant difference of helminth infection with regard to gender $(P=0.97)$, mothers' education $(P=0.7)$, family size $(P=0.5)$, and fathers' and mothers' occupation $(P=0.5) \quad$ (Table 1$)$. The most frequently encountered helminth was S. mansoni (12.9\%) followed by hookworms (4.3\%). The overall infection intensity of helminths expressed as geometric mean among the study participants for Ascaris lumbricoides (A. lumbricoides), Trichuris trichiura (T. trichiura), hookworms, and S. mansoni was 301, 31, 103, and 158 EPG, respectively. Most of the children had light infections, while $35.2 \%$ and $25.9 \%$ of children with S.mansoni infection had moderate and heavy infection intensity, respectively (Table 3 ).

\section{Factors associated with helminth infections}

Children within the age group of $5-9$ years (COR 1.2, 95\% CI 1.3-2.1) and children whose family use river water for washing raw food and vegetables (COR 2.1, 95\% CI 1.3-3.3) had significantly higher helminth infection (Table 2). Similarly, significantly higher helminth infection was observed in children with a habit of bathing in the river (COR 1.9, 95\% CI 1.1-2.2) compared to those with a habit of bathing in the home using tap water (Table 2).

The multivariable logistic regression model estimated that children within the age group of 5-9 years were 1.43 times (AOR 1.43, 95\% CI 0.4-0.9) more likely to get infected with helminths than those within the age group of 10-14 years(Table 1). Besides, the odds of helminth infection was 2.4 times (AOR 2.4, 95\% CI 16-0.75) more for children whose family use river water for washing raw food and vegetables as compared to children's family who uses tap water for washing raw food and vegetables. Children who had a regular bathing habit in the river were 2.1 times (AOR
2.1, 95\%CI $0.3-0.9)$ more likely to get infected with helminths than children who had a regular bathing habit of in the home using tap water (Table 2).

\section{Discussion}

Since Ethiopia launched the national MDA program in November 2015 [20], the control strategy in the country aims to eliminate STHs and schistosomiasis-related morbidity and to reduce the prevalence of heavy infection to less than $1 \%$ by 2020 [14]. The present study attempted to determine the status, infection intensity, and factors associated with helminths among SAC in Guragae zone. A survey provides pertinent information regarding the current status of helminths in the study area and enables evidence-based decision to be made in due course of the targeted elimination (Table 3 ).

The fact that deworming does not prevent re-infection, repeated deworming has been known to have a considerable impact on maintaining the infection intensity of helminths to a minimal level, reducing the associated morbidities among infected individuals [25]. The overall intestinal parasite prevalence before the country-wide deworming program in the study area was ranging between 38.5 and $40 \%$ [19]. After 3 years of consecutive annual deworming, helminth infections have been prevalent in the study area. According to WHO STH and schistosomiasis endemic area classifications [9], the study area would be classified into the moderate transmission group and have been calling for annual deworming.

In Ethiopia, since the launch of the national MDA program, over 19 million people have been treated for schistosomiasis and the treatment coverage for schistosomiasis was $77 \%$ with $100 \%$ geographical coverage [14]. But, in the present study, S.mansoni was the most prevalent species of helminths and the majority of S.mansoni-infected children were classified under moderate to heavy infection intensity category. These may due to the impact of deworming depends on a variety of factors, including therapeutic efficacy of drugs used [26], the frequency at which deworming is given [27], individual factors, and the underlying intensity of parasite transmission [28]. In addition, the helminth transmission rate is influenced by environmental conditions that influence the survival and development of helminths free-living stages and socioeconomic factors which influence rates of exposure to infective stages [2].

Helminth infection is peaked in children aged between 4 and 8 years due to increased exposure with age and maintained constant possibly due to host resistance development and less exposure. However, there is no permanent development of protective immunity to re-infection [29]. In support of this, the prevalence of helminths in the present study showed significantly 
Table 1 Helminth infection in relation to sociodemographic characteristics among schoolchildren in the endemic area of Guragae zone, Southern Ethiopia, 2017

\begin{tabular}{|c|c|c|c|c|c|c|c|}
\hline \multirow[t]{2}{*}{ Variables } & \multirow{2}{*}{$\begin{array}{l}\text { Total, } \\
\text { N (\%) }\end{array}$} & \multicolumn{2}{|c|}{ Helminth infection } & \multirow[t]{2}{*}{ COR $(95 \% \mathrm{Cl})$} & \multirow[t]{2}{*}{$P$} & \multirow[t]{2}{*}{ AOR $(95 \% \mathrm{Cl})$} & \multirow[t]{2}{*}{$P$} \\
\hline & & Positive, N (\%) & Negative, $N(\%)$ & & & & \\
\hline \multicolumn{8}{|l|}{ Age group in years } \\
\hline $5-9$ & $318(53.2)$ & $77(24.2)$ & $241(75.8)$ & $1.2(1.9-2.1)$ & $0.03^{*}$ & $1.43(0.4-0.9)$ & $0.031^{*}$ \\
\hline $10-14$ & $279(46.7)$ & $52(18.6)$ & $227(81.4)$ & 1 & & 1 & \\
\hline \multicolumn{8}{|l|}{ Gender } \\
\hline Female & $247(41.3)$ & $51(20.6)$ & $196(79.4)$ & 1 & & & \\
\hline Male & $350(58.7)$ & 78 (22.2) & $272(77.8)$ & 0.97 & 0.632 & - & - \\
\hline \multicolumn{8}{|l|}{ Fathers' education } \\
\hline No formal education & $205(34.3)$ & $50(24.3)$ & $155(75.7)$ & 3.1 & 0.2 & $1.4(0.1-19)$ & 0.7 \\
\hline Primary & $293(49.1)$ & $63(21.5)$ & $230(78.5)$ & 3.6 & 0.2 & $1.6(0.1-22)$ & 0.7 \\
\hline Secondary & $80(13.4)$ & $10(12.5)$ & $69(87.5)$ & 6.2 & 0.08 & $2.6(0.1-36)$ & 0.4 \\
\hline Diploma and above & $19(3.2)$ & $6(31.5)$ & $14(68.5)$ & 1 & & 1 & \\
\hline \multicolumn{8}{|l|}{ Mothers' education } \\
\hline No formal education & $276(46.2)$ & $60(21.7)$ & $216(78.3)$ & 1.3 & 0.2 & $1.6(0.1-14)$ & 0.6 \\
\hline Primary & $277(46.3)$ & $61(28.2)$ & $216(71.8)$ & 1.3 & 0.3 & $1.4(0.1-13)$ & 0.7 \\
\hline Secondary & $33(5.5)$ & $5(15.1)$ & $28(84.9)$ & 2.1 & 0.1 & $1.5(0.1-15)$ & 0.7 \\
\hline Diploma and above & $11(2.0)$ & $3(27.2)$ & $8(72.8)$ & 1 & & 1 & \\
\hline \multicolumn{8}{|l|}{ Mothers' occupation } \\
\hline Farmer & $70(11.7)$ & $20(28.5)$ & $50(77.5)$ & 1 & & & \\
\hline Merchant & $127(21.3)$ & $27(21.2)$ & $100(78.8)$ & 1.48 & 0.3 & & \\
\hline Housewife & $377(63.10$ & 79 (20.9) & $298(79.1)$ & 1.5 & 0.32 & & \\
\hline Others $^{b}$ & $23(3.9)$ & $3(13.1)$ & $20(86.9)$ & 1.86 & 0.3 & & \\
\hline \multicolumn{8}{|l|}{ Fathers' occupation } \\
\hline Farmer & $389(65.1)$ & $95(24.4)$ & $294(75.6)$ & 1 & & & \\
\hline Merchant & 95 (15.9) & $16(16.8)$ & 79 (83.2) & 1.6 & 0.1 & $1.4(0.7-2)$ & 0.2 \\
\hline Employed & $63(10.5)$ & $11(17.4)$ & $52(82.6)$ & 1.5 & 0.1 & $1.3(0.5-3)$ & 0.5 \\
\hline Daily labor & $37(6.1)$ & $4(10.8)$ & $33(99.2)$ & 2.6 & 0.07 & $2.4(0.2-5)$ & 0.1 \\
\hline Others $^{b}$ & $13(2.4)$ & $3(23.1)$ & $10(76.9)$ & 1.6 & 0.5 & $1.06(0.2-5)$ & 0.9 \\
\hline \multicolumn{8}{|l|}{ Residence } \\
\hline Urban & $310(51.9)$ & $63(20.3)$ & $247(79.7)$ & 1 & & & \\
\hline Rural & $287(48.1)$ & $66(22.9)$ & $221(77.1)$ & 1.17 & 0.4 & - & - \\
\hline \multicolumn{8}{|l|}{ Family size } \\
\hline Less than 5 & $231(38.6)$ & $48(20.7)$ & $183(79.3)$ & 1 & & & \\
\hline Between 5 and 10 & $353(59.1)$ & 80 (22.6) & $273(77.4)$ & 1.14 & 0.5 & $0.882(0.5-1.3)$ & 0.5 \\
\hline Greater than 10 & $13(2.3)$ & $1(7.6)$ & $12(92.4)$ & 3.14 & 0.2 & $3(0.4-26)$ & 0.2 \\
\hline
\end{tabular}

COR crude odds ratio, AOR adjusted odds ratio, $C l$ confidence interval, $P P$ value, $N$ number *Statistically significant at $P<0.05$

${ }^{\text {b }}$ Student, daily laborer

higher in age ranging from 5 to 9 years. A similar trend result was also observed in other studies conducted elsewhere [30, 31].

Washing raw food or vegetables using river water and bathing place were other key factors significantly associated with helminth infections in the present study. The finding is comparable with previous reports from the study area [19]. These results might indicate that using protected water and bathing place could contribute to a reduction in the prevalence of helminth infection. This highlighted that deworming should be backed up with health education to prevent re-infection for integrated control of helminths. Hence, increased coordination between deworming and health education program is 
Table 2 Factors associated with helminth infection among schoolchildren in the endemic area of Guragae zone, Southern Ethiopia, 2017

\begin{tabular}{|c|c|c|c|c|c|c|c|}
\hline \multirow[t]{2}{*}{ Variables } & \multirow{2}{*}{$\begin{array}{l}\text { Total, } \\
N(\%)\end{array}$} & \multicolumn{2}{|c|}{ Helminth infection } & \multirow{2}{*}{$\begin{array}{l}\text { COR }(95 \% \\
\mathrm{Cl})\end{array}$} & \multirow[t]{2}{*}{$P$} & \multirow[t]{2}{*}{ AOR $(95 \% \mathrm{Cl})$} & \multirow[t]{2}{*}{$P$} \\
\hline & & Positive, N (\%) & Negative, $N(\%)$ & & & & \\
\hline \multicolumn{8}{|l|}{ Water for drinking } \\
\hline From tap & $539(90.2)$ & $114(21.2)$ & $425(78.8)$ & 1 & & & \\
\hline Protected well & $45(7.5)$ & $13(28.8)$ & $32(71.2)$ & & & & \\
\hline From river & $11(2.3)$ & $2(18.1)$ & $11(81.9)$ & 4 & 0.99 & & \\
\hline \multicolumn{8}{|c|}{ Water for washing raw food and vegetables } \\
\hline From tap & $380(63.6)$ & $67(17.6)$ & $313(82.4)$ & 1 & & 1 & \\
\hline Unprotected well & $62(10.3)$ & $14(22.5)$ & $48(77.5)$ & $2.1(1.3-3.3)$ & $0.001^{*}$ & $0.35(0.1-0.8)$ & 0.9 \\
\hline Protected well & $9(1.5)$ & $2(22.2)$ & $7(77.8)$ & 1.5 & 0.196 & $1.03(0.1-3.5)$ & 0.5 \\
\hline From the river & $146(24.6)$ & $46(31.5)$ & $100(68.5)$ & 1.6 & 0.562 & $2.4(0.16-0.75)$ & $0.008^{*}$ \\
\hline \multicolumn{8}{|l|}{ Fingernail status } \\
\hline Trimmed & $285(47.7)$ & $57(20.0)$ & $228(80.0)$ & 1 & & 1 & \\
\hline Untrimmed & $312(52.3)$ & $72(23.1)$ & $240(76.7)$ & 4 & 0.15 & $4.5(0.3-1.2)$ & 0.22 \\
\hline \multicolumn{8}{|l|}{ Shoe wearing habit } \\
\hline Always & $588(98.4)$ & $128(21.4)$ & $460(78.6)$ & 0.61 & 0.5 & & \\
\hline Sometimes & $9(1.6)$ & $1(11.1)$ & $8(88.9)$ & 1 & & & \\
\hline \multicolumn{8}{|c|}{ Hand washing habit after defecation } \\
\hline Always & $347(58.1)$ & $78(22.4)$ & $256(77.6)$ & 1 & & & \\
\hline Sometimes & $250(40.9)$ & $51(20.4)$ & $202(79.6)$ & 1.01 & 0.9 & & \\
\hline \multicolumn{8}{|c|}{ Hand washing habit before eating meal } \\
\hline Always & $218(36.5)$ & $51(23.4)$ & $167(76.6)$ & 0.001 & 0.9 & & \\
\hline Sometimes & $379(63.5)$ & $78(20.5)$ & $301(79.5)$ & 1 & & & \\
\hline \multicolumn{8}{|l|}{ Latrine availability } \\
\hline Yes & $566(94.8)$ & $121(21.4)$ & $445(78.6)$ & 1 & & & \\
\hline No & $31(5.2)$ & $8(25.8)$ & $23(74.2)$ & 1.29 & 0.56 & & \\
\hline \multicolumn{8}{|l|}{ Latrine type } \\
\hline Flush latrine & $94(15.7)$ & $23(24.5)$ & $71(75.5)$ & 1 & & & \\
\hline Pit Latrine & $503(84.3)$ & $106(17.8)$ & $397(82.2)$ & 1.23 & 0.4 & & \\
\hline \multicolumn{8}{|l|}{ Latrine utilization } \\
\hline Latrine & $490(82.1)$ & $103(21.1)$ & $387(78.9)$ & 1 & & & \\
\hline Open filled & $107(17.9)$ & $26(24.2)$ & $81(75.8)$ & 1.22 & 0.4 & & \\
\hline \multicolumn{8}{|l|}{ Bathing place } \\
\hline Home & $341(57.1)$ & $83(24.3)$ & $253(75.7)$ & 1 & & 1 & \\
\hline River & $179(29.9)$ & $28(15.6)$ & $151(84.4)$ & $1.9(1.1-2.1)$ & $0.009^{*}$ & $2.14(0.3-0.9)$ & $0.04^{*}$ \\
\hline Others & $77(13.0)$ & $12(15.5)$ & $62(84.5)$ & 1.79 & 0.84 & & \\
\hline \multicolumn{8}{|l|}{ Habit on soil playing } \\
\hline Yes & $315(52.7)$ & $122(20.4)$ & $249(79.6)$ & 1 & & & \\
\hline No & $282(47.3)$ & $43(15.2)$ & $219(84.8)$ & 0.56 & 0.77 & & \\
\hline \multicolumn{8}{|l|}{ Nail biting habit } \\
\hline No & $315(52.7)$ & $71(22.5)$ & $244(77.5)$ & 1 & & & \\
\hline Some times & $282(47.3)$ & $58(20.5)$ & $224(79.5)$ & 2.1 & 0.21 & $1.3(0.3-1.66)$ & 0.1 \\
\hline
\end{tabular}


Table 3 Infection intensity of schoolchildren infected with helminths in the endemic area of Guragae zone, Southern Ethiopia, 2017

\begin{tabular}{llllll}
\hline Helminths & $\begin{array}{l}\text { Number } \\
(\%)\end{array}$ & $\begin{array}{l}\text { Geometric } \\
\text { mean (EPG) }\end{array}$ & $\begin{array}{l}\text { Light, } \\
\text { no. (\%) }\end{array}$ & $\begin{array}{l}\text { Moderate, } \\
\text { no. (\%) }\end{array}$ & $\begin{array}{l}\text { Heavy, } \\
\text { no. }(\%)\end{array}$ \\
\hline $\begin{array}{l}\text { Hookworms } \\
\text { 26/597 (4.3) }\end{array}$ & 103 & $26(100)$ & & \\
$\begin{array}{l}\text { Ascaris } \\
\text { lumbricoides }\end{array}$ & $18 / 597(3)$ & 301 & $18(100)$ & & \\
$\begin{array}{l}\text { Trichuris } \\
\text { trichiura }\end{array}$ & $3 / 597(0.5)$ & 31 & $3(100)$ & & \\
$\begin{array}{l}\text { Schistosoma } \\
\text { mansoni }\end{array}$ & $\begin{array}{l}77 / 597 \\
(12.9)\end{array}$ & 158 & 30 & $27(35.2)$ & $20(25.9)$ \\
*Others & $17 / 597(2.8)$ & - & $(38.9)$ & & \\
helminths & & & & & \\
Helminth & $12 / 597(2.1)$ & - & & & \\
co-infection & & & & & \\
Total & $141 / 597$ & 112 & & & \\
& $(23.6)$ & & & & \\
\end{tabular}

*Enterobius vermicularis, Hymenolepis species

essential to achieve the targeted elimination goals within the targeted time in the study area.

The present study had its own limitations; since only a single stool specimen was collected from each child, there might be an underestimation of the prevalence of helminths because of the temporal variation in egg excretion over hours and days. In addition, the study design being cross-sectional could underline the causal association between the helminths and socio-economic and demographic variables. Nevertheless, proportionate systematic sampling of the SAC from school would make it possible to generalize the finding to the whole SAC in the study area.

\section{Conclusions}

Despite the fact that Ethiopia planned to eliminate helminth infection-related morbidity by 2020 , the present study showed that helminth infection was prevalent among SAC in the study area. Moreover, poor personal hygiene such as regular bathing habit in the river and using river water for washing raw food and vegetables were the key factors significantly associated with helminth infections. Hence, efforts should be made to improve hygienic practices in addition to the school-based deworming program. The authors also believe that the deworming program should also focus on reaching those SAC who are not attending school through communal social places to achieve the targeted goal in the study area in particular and in the country in general.

\section{Abbreviations}

EPG: Eggs per gram; MDA: Mass drug administration; SAC: School-aged children; SSA: Sub-Saharan Africa; STHs: Soil-transmitted helminths; WHO: World Health Organization

\section{Acknowledgements}

The authors would like to sincerely thank the head of the zonal and each district's health offices, school directors, data collectors, and study participants.

\section{Funding \\ The study was sponsored by Wolkite University.}

\section{Availability of data and materials}

The datasets used and/or analyzed during the current study are available from the corresponding author on reasonable request.

\section{Authors' contributions}

TS conceived the study, participated in the study design and data analysis, drafted the manuscript, and coordinated the laboratory work. TG participated in the data analysis and preparation of the manuscript. Both authors read and approved the final manuscript.

\section{Ethics approval and consent to participate}

The study protocols were reviewed and approved by the Ethical Review Committee of Wolkite University (Ref.No.RCSUIL/79/09). Letters of permission were obtained from Gurage zone health department and each district's health office. The objectives as well as the nature of the study explained to the school directors. Written informed consent was obtained from each children parent or their guardian. Data collected from each study participant and results of laboratory tests were kept confidential. Children with positive stools for any helminths were treated with a single dose of $100 \mathrm{mg}$ mebendazole tablets as recommended by the national guideline [32].

\section{Consent for publication}

Not applicable.

\section{Competing interests}

The authors declare that they have no competing interests.

\section{Publisher's Note}

Springer Nature remains neutral with regard to jurisdictional claims in published maps and institutional affiliations.

\section{Author details}

'Department of Medical Laboratory Sciences, College of Medicine and Health Sciences, Wolkite University, Wolkite, Ethiopia. ${ }^{2}$ Department of Public Health, College of Medicine and Health Sciences, Wolkite University, Wolkite, Ethiopia.

Received: 15 November 2018 Accepted: 8 April 2019

Published online: 03 May 2019

\section{References}

1. Eppig C, Fincher $\mathrm{CL}$, Thornhill R. Parasite prevalence and the worldwide distribution of cognitive ability. Proc Biol Sci. 2010;277(1701):3801-8.

2. Ojha SC, Jaide C, Jinawath N, Rotjanapan P, Baral P. Geohelminths: public health significance. J Infect Dev Ctries. 2014;8(01):005-16.

3. World Health Organization. Soil-transmitted helminthiases: eliminating as public health problem soil-transmitted helminthiases in children: progress report 2001-2010 and strategic plan 2011-2020: WHO; 2012. http://wwW. who.int/iris/handle/10665/44804.

4. Daumerie D, Savioli L. Working to overcome the global impact of neglected tropical diseases: first WHO report on neglected tropical diseases (Vol. 1): WHO; 2010

5. Jourdan PM, Lamberton PH, Fenwick A, Addiss DG. Soil-transmitted helminth infections. Lancet. 2018;391(10117):252-65.

6. Farrell SH, Coffeng LE, Truscott JE, Werkman M, Toor J, de Vlas SJ, et al. Investigating the effectiveness of current and modified World Health Organization Guidelines for the Control of Soil-Transmitted Helminth Infections. Clin Infect Dis. 2018;66(suppl_4):S253-S9.

7. Lustigman S, Prichard RK, Gazzinelli A, Grant WN, Boatin BA, McCarthy JS, et al. A research agenda for helminth diseases of humans: the problem of helminthiases. Plos Neglect Trop D. 2012;6(4):e1582.

8. Deribew A, Kebede B, Tessema GA, Adama Y, Misganaw A, Gebre T, et al. Mortality and disability-adjusted life-years (Dalys) for common neglected 
tropical diseases in Ethiopia, 1990-2015: evidence from the Global Burden of Disease Study 2015. EMJ. 2017;55(Suppl 1):3.

9. World Health Organization. Research priorities for helminth infections: technical report of the TDR disease reference group on helminth infections. Technical report series; no. 972 WHO 2012.

10. Lo NC, Addiss DG, Hotez PJ, King CH, Stothard JR, Evans DS, et al. A call to strengthen the global strategy against schistosomiasis and soil-transmitted helminthiasis: the time is now. Lancet Infect Dis. 2017;17(2):e64-e9.

11. Speich B, Croll D, Fürst T, Utzinger J, Keiser J. Effect of sanitation and water treatment on intestinal protozoa infection: a systematic review and metaanalysis. Lancet Infect Dis. 2016;16(1):87-99.

12. World Health Organization. Investing to overcome the global impact of neglected tropical diseases: third WHO report on neglected tropical diseases 2015 (Vol. 3): WHO; 2015

13. Karagiannis-Voules D-A, Biedermann P, Ekpo UF, Garba A, Langer E, Mathieu $E$, et al. Spatial and temporal distribution of soil-transmitted helminth infection in sub-Saharan Africa: a systematic review and geostatistical metaanalysis. Lancet Infect Dis. 2015;15(1):74-84.

14. Negussu N, Mengistu B, Kebede B, Deribe K, Ejigu E, Tadesse G, et al. Ethiopia schistosomiasis and soil-transmitted helminthes control programme: progress and prospects. EMJ. 2017;55(Suppl 1):75.

15. Samuel F. Status of soil-transmitted helminths infection in Ethiopia. Am J Health Res. 2015;3(3):170-6.

16. Bajiro M, Dana D, Ayana M, Emana D, Mekonnen Z, Zawdie B, et al. Prevalence of Schistosoma mansoni infection and the therapeutic efficacy of praziquantel among school children in Manna District, Jimma Zone, Southwest Ethiopia. Parasit Vectors. 2016;9(1):560.

17. Alemayehu B, Tomass Z, Wadilo F, Leja D, Liang S, Erko B. Epidemiology of intestinal helminthiasis among school children with emphasis on Schistosoma mansoni infection in Wolaita zone, Southern Ethiopia. BMC Public Health. 2017;17(1):587.

18. Alemu A, Atnafu A, Addis Z, Shiferaw Y, Teklu T, Mathewos B, et al. Soil transmitted helminths and Schistosoma mansoni infections among school children in Zarima town, Northwest Ethiopia. BMC Infect Dis. 2011;11(1):189.

19. Melesse B, Kelebesa U, Beyene P. Prevalence and determinants of intestinal parasitic infections among primary schoolchildren in Gurage zone, South Central Ethiopia. EC Microbiol. 2017:8(2):59-70.

20. Mengitsu B, Shafi O, Kebede B, Kebede F, Worku DT, Herero M, et al. Ethiopia and its steps to mobilize resources to achieve 2020 elimination and control goals for neglected tropical diseases: spider webs joined can tie a lion. Int Health. 2016;8(suppl_1):i34-52.

21. Bockarie MJ, Kelly-Hope LA, Rebollo M, Molyneux DH. Preventive chemotherapy as a strategy for elimination of neglected tropical parasitic diseases: endgame challenges. Phil Trans R Soc B. 2013;368(1623):20120144.

22. Shumbej T, Belay T, Mekonnen Z, Tefera T, Zemene E. Soil-transmitted helminths and associated factors among pre-school children in Butajira Town, South-Central Ethiopia: a community-based cross-sectional study. PLoS One. 2015;10(8):e0136342.

23. Melvin DM, Brooke MM, Centers for Disease Control (U.S.). Laboratory Training and Consultation Division. Laboratory Procedures for the Diagnosis of Intestinal Parasites. 3rd ed., 1982. Atlanta: U.S. Dept. of Health and Human Services, Public Health Service, Centers for Disease Control, Laboratory Improvement Program Office, Laboratory Training and Consultation Division; 1985.

24. Montresor A, Crompton DW, Gyorkos TW, Savioli L. Helminth control in schoolage children: a guide for managers of control programmes: WHO; 2002. http:// www.who.int/iris/handle/10665/42473.

25. Anderson R, Truscott J, Hollingsworth TD. The coverage and frequency of mass drug administration required to eliminate persistent transmission of soil-transmitted helminths. Phil Trans R Soc B. 2014;369(1645):20130435.

26. Schulz JD, Moser W, Hürlimann E, Keiser J. Preventive chemotherapy in the fight against soil-transmitted helminthiasis: achievements and limitations. Trends Parasitol. 2018.

27. Palmeirim MS, Hürlimann E, Knopp S, Speich B, Belizario V Jr, Joseph SA, et al. Efficacy and safety of co-administered ivermectin plus albendazole for treating soil-transmitted helminths: a systematic review meta-analysis and individual patient data analysis. Plos Neglect Trop D. 2018;12(4): e0006458.

28. Cundill B, Alexander N, Bethony JM, Diemert D, Pullan RL, Brooker S. Rates and intensity of re-infection with human helminths after treatment and the influence of individual, household, and environmental factors in a Brazilian community. J Parasit. 2011;138(11):1406-16.

29. World Health Organization. Communicable diseases and severe food shortage: WHO technical note, October 2010. Geneva: WHO; 2010

30. Unasho A. An investigation of intestinal parasitic infections among the asymptomatic children in, Southern Ethiopia. Int J Child Health Nutr. 2013; 2(3):212-22.

31. Haileamlak A. Intestinal parasites in asymptotic children in Southwest Ethiopia. Ethiop J Health Sci. 2005;15(2):107-118.

32. EFMHACA. Ethiopian medicines formulary. 2nd ed. Addis Ababa: Food, Medicine and Healthcare Adminstration and Control Authority of Ethiopia; 2013.
Ready to submit your research? Choose BMC and benefit from:

- fast, convenient online submission

- thorough peer review by experienced researchers in your field

- rapid publication on acceptance

- support for research data, including large and complex data types

- gold Open Access which fosters wider collaboration and increased citations

- maximum visibility for your research: over $100 \mathrm{M}$ website views per year

At BMC, research is always in progress.

Learn more biomedcentral.com/submissions 